\title{
EVALUASI PENERAPAN LAPORAN ARUS KAS BERDASARKAN STANDAR AKUNTANSI KEUANGAN ENTITAS TANPA AKUNTABILITAS PUBLIK (SAK ETAP) PADA PERUSAHAAN PT. AIR MANADO
}

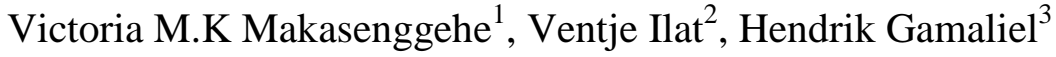 \\ 1,2,3 Jurusan Akuntansi, Fakultas Ekonomi dan Bisnis, Universitas Sam Ratulangi, Jl. Kampus Bahu, Manado \\ 95115, Indonesia
}

Email : indah.makasenggehe@gmail.com

\begin{abstract}
The cash flow report presents information on historical changes in cash and cash equivalents of the entity, which shows separately the changes that occur during one period of operating, investing and funding activities. The main purpose of the cash flow statement is the financial position report provides information on net cash inflows in a period, the results of the three main activities of the company are operations, investments and funding. SAK ETAP provides many facilities for companies compared to PSAK with more complex reporting provisions. In accordance with the scope of SAK ETAP, this standard is intended to be used by entities without public accountability (entities that do not have significant public accountability; and do not publish general-purpose financial statements). The presence of Entity Accounting Standards without Public Accountability (SAK ETAP) is expected to provide convenience for PT. Air Manado in presenting financial statements. The purpose of SAK ETAP itself is to provide facilities for small and medium scale entities. In accordance with SAK-ETAP, Entities without intended public accountability are entities that do not have significant public accountability and publish general-purpose financial reports for external users. This study uses a type of descriptive research - comparative. The results showed that PT. Air Manado has implemented financial statements in accordance with applicable standards but there are still items or elements in the cash flow statement that have not fully implemented the Entity Financial Accounting Standards without Public Accountability (SAK ETAP) in the cash flow statement.
\end{abstract}

Keyword : SAK ETAP, Cash Flow Report,Financial Accounting,PT. Air Manado,Public Accountability

\section{PENDAHULUAN}

Setiap perusahaan memiliki tujuan untuk mendapatkan laba, Laba merupakan salah satu tujuan utama kinerja perusahaan. Untuk itu harus ada prosedur kinerja perusahaan untuk memperoleh keuntungan dalam Arus Kas, arus kas menyajikan informasi perubahan historis atas kas dan setara kas entitas, yang menunjukkan secara terpisah perubahan yang terjadi selama satu periode dan aktivitas operasi, investasi, dan pendanaan.

Arus kas dalam perusahaan bisa dilihat dari aktivitas dalam perusahaan, sebab semua aktivitas perusahaan bermaksud menghasilkan kas. Aktivitas-aktivitas yang berjalan dalam perusahaan berdasarkan dampaknya terhadap kas secara garis besar dapat di klasifikasikan pada aktivitas operasi, aktivitas investasi dan aktivitas pendanaan. Peraturan akuntansi yang berlaku di Indonesia yang di sebut Standar Akutansi Keuangan mensyaratkan perusahaan untuk menjadikan laporan arus kas dengan mengungkapkan aliran kas masuk dan aliran kas keluar berdasarkan aktivitas-aktivitas perusahaan. 


\section{TINJAUAN PUSTAKA}

Konsep Akuntansi. Choi \& Meek, (2011:1) Akuntansi merupakan cabang ilmu ekonomi yang menyediakan informasi mengenai perusahaan dan transaksinya untuk memfasilitasi keputusan alokasi sumber daya oleh para pengguna informasi tersebut. Menurut Tanor, 2015 Akuntansi adalah suatu seni pencatatan, penggolongan, dan peringkasan dengan cara yang informatif dan diukur dalam bentuk mata uang, atas transaksitransaksi atau kejadian-kejadian keuangan perusahaan dan interpretasi hasilnya. Hery, (2012:7) Mula-mula sebuah transaksi bisnis akan diidentifikasi (dianalis), dicatat dan barulah dilaporkan akuntansi yang merupakan media komunikasi informasi akuntansi. Hillinger, (2010) Akuntansi untuk bank yang memiliki aset di luar neraca yang umumnya memungkinkan perusahaan untuk menghindari pengungkapan yang salah atau kehilangan uang aset kepada investor untuk membuat perusahaan tampak lebih berharga daripada itu.

Konsep Akuntansi Keuangan. Effendi, Rizal. (2014:5) penyusunan informasi akuntansi yang berupa laporan keuangan terutama ditujukan untuk pihak luar perusahaan:. Oleh sebab itu, laporan keuangan disajikan hendaknya atas prinsip akuntansi yang berlaku.

Konsep Laporan Keuangan. Menurut SAK ETAP (2014:3,2) Laporan keuangan menyajikan dengan wajar posisi keuangan, kinerja keuangan, dan arus kas suatu entitas.

Pelaporan Keuangan Entitas Tanpa Akuntabilitas Publik. Menurut Ikatan Akuntan Indonesia dalam SAK ETAP (2009) laporan keuangan adalah bagian dari proses pelaporan keuangan, dan laporan keuangan yang lengkap meliputi : neraca, laporan laba rugi, laporan perubahan modal, laporan arus kas, dan catatan atas laporan keuangan.

Standar Akunatnsi Keuangan (SAK). Surya (2012:6) SAK adalah pernyataan dan interpretasi yang disusun oleh Dewan Standar Akuntansi Keuangan Ikatan Akuntansi Indonesia (DSAK IAI), terdiri dari Pernyataan Standar Akuntansi Keuangan (PSAK) dan Interpretasi Standar Akuntansi Keuangan (ISAK).

Laporan Arus Kas. Tukunang (2014) Arus kas merupakan laporan untuk menentukan perubahan kas selama satu periode tertentu dan memberikan penjelasan mengenai alasan perubahan tersebut dengan menetukan dari mana sumber penerimaan kas dan untuk apa penggunaanya seperti kegiatan operasional, pembiayaan, dan investasi.

Penelitian Terdahulu. Pratiwi (2014) dengan judul "Analisis Penerapan SAK ETAP pada penyajian Laporan Keuangan PT. NICHINDO SUSAN MANADO" hasil penelitian Neraca dan Laporan Laba Rugi tahun 2011 dan 2012, menandakan bahwa perusahaan belum menyajikan laporan perubahaan ekuitas, laporan arus kas, dan catatan atas laporan keuangan (CALK) serta menjadi konsistensi dalam penyajian beberapa pos pada Neraca yang tidak diungkapkan dalam CALK. Wehantouw (2015) dengan judul "Analisis Laporan Arus Kas Operasi, Investasi dan Pendanaan Pada PT. Gudang Garam Tbk" hasil penelitian Menunjukan PT. Gudang Garam, pada biasanya mempunyai laporan arus kas yang baik dapat dilihat dari setiap rata-rata perbandingan arus kas yang ada. Meireny (2015) dengan judul "Analisis Penyusunan Laporan Keuangan Berdasarkan SAK ETAP Pada Koperasi Pasar Gondanglegi” yang hasil penelitian Membuktikan bahwa pada proses pelaksanaan siklus akuntansi yang ada, KPG tidak melakukan pencatatan atas pencatatan transaksi dalam buku jurnal (journal entry) dan pencatatan ayat jurnal ke buku besar (posting ledger) yang sesuai dengan SAK ETAP dan siklus akuntansi secara umum.

\section{METODE PENELITIAN}

Jenis Penelitian. Penelitian yang digunakan deskriptif kualitatif bertujuan mendalami keadaan yang terjadi di PT. Air Manado tentang laporan arus kas dan hasilnya dapat dideskripsikan dalam laporan penelitian.

Tempat dan Waktu Penelitian. Penelitian ini dilaksanakan pada PT. Air Manado. Penelitian ini dilakukan sampai 2 sampai 3 bulan. 
Jenis, Sumber dan Metode Pengumpulan Data. Penelitian deskriptif meliputi pengumpulan data untuk diuji hipotesis atau menjawab pertanyaan mengenai situs terakhir dari subjek penelitian (Sunyoto, 2013). Sumber data digunakan dalam penelitian ini adalah data primer, yang di dapat langsung dari perusahaan yang berupa wawancara dengan manager bidang keuangan serta dokumentasi yang berupa laporan keuangan PT. Air Manado. Data sekunder yang dipakai adalah data (1) wawancara; (2) dokumentasi; (3) media elektronik.

Metode dan Proses Analisis. Metode analisis digunakan penelitian ini adalah metode analisis kualitatif deskriptif, yaitu menjelaskan tentang Evaluasi Penerapan Laporan arus Kas Berdasarkan Standar Akuntansi Keuangan Entitas Tanpa Akuntabilitas Publik (SAK ETAP) pada PT. Air Manado. 


\section{HASIL ANALISIS DAN PEMBAHASAN}

\subsection{Hasil Analisis}

Berdasarkan hasil wawancara yang dilakukan dengan bagian keuangan PT. Air Manado sendiri maka di peroleh informasi yaitu, perusahaan PT.Air Manado bergerak di dalam bidang Jasa dikhususkan untuk menyediakan kebutuhan air, PT. Air Manado adalah perusahaan yang non go public. Dalam Laporan Arus Kas yang ada di PT. Air Manado di ambil 3 tahun terakhir yakni tahun 2014,2015,dan 2016. PT. Air Manado membuat laporan keuangan yang bertujuan untuk menyediakan informasi keuangan pada periode tertentu bagi pihak-pihak yang berkepentingan dan juga sebagai bahan pertimbangan dalam mengambil suatu keputusan oleh perusahaan. PT. Air Manado membuat laporan keuangan per periode dan Laporan Arus kas dibuat dalam perperiode.

Berdasarkan Standar Akuntansi Keuangan Entitas Tanpa Akuntabilitas Publik laporan keuangan entitas yang sesuai dengan SAK ETAP merupakan laporan keuangan yang di dalamnya terdapat laporan yang tedriri dari 5 jenis yaitu Neraca, Laporan Laba Rugi, Laporan Perubahan Ekuitas, Laporan Arus Kas, dan Catatan Atas Laporan Keuangan. Sesuai judul dan masalah penelitian penulis hanya meneliti dan membahas laporan Arus kas.

Laporan Arus Kas. Aktivitas Operasi Arus kas dari aktivitas operasi terutama diperoleh dari aktivitas penghasil utama pendapatan entitas. Arus kas dari aktivitas investasi mengambarkan pengeluaran kas sehubungan dengan sumber daya yang bertujuan untuk menghasilkan pendapatan dan arus kas masa depan. Arus kas dari aktivitas pendanaan. 
Laporan Arus Kas PT.Air Manado tahun 2014,2015 dan 2016

\section{ARUS KAS DARI AKTIVITAS OPERASI}

Laba (Rugi) Bersih Penyesuaian Untuk

1.481 .172 .619

Penyusutan Aktiva Tetap \& Amortisasi

6.850 .051 .756

Laba (Rugi) Bersih Operasi Sebelum Perubahan Modal Kerja

Perubahan Modal Kerja

- Piutang Usaha

$(5.042 .433 .412)$

- Penyisihan Piutang Usaha

5.199 .233 .975

- Piutang Lain-Lain

482.866 .712

- Piutng ke PDAM

$(294.808 .571)$

- Persediaan

114.306 .612

- Biaya dibayar dimuka

79.263 .500

- Hutang Jangka Pendek

(2.617.211.812)

- Jutang Jangka Panjang

$(3.987 .585 .431)$

Arus Kas Bersih yang Dihasilkan (Digunakan) Untuk Aktivitas Operasi (I)

ARUS KAS DARI AKTIVITAS INVESTASI

Aktivitas Investasi

- Aktiva tetap

$(2.831 .049 .923)$

- Investasi

- Aktiva Lain-Lain

Arus Kas Bersih yang Dihasilkan (Digunakan) Untuk Aktivitas Operasi (II)

ARUS KAS DARI AKTIVITAS PENDANAAN

Aktivitas pendanaan

- Modal Tambahan

- Laba (Rugi) Ditahan

(194.332.674)

Arus Kas Bersih yang Dihasilkan (Digunakan) Untuk Aktivitas Pendanaan

(194.332.674)

Kenaikan Bersih Kas dan Setara Kas (I+II+III)

(760.526.648)

Kas dan Setara Kas Pada Awal Periode

966.013 .891

Kas dan Setara Kas Pada Akhir Periode 
Laporan Arus Kas 2015

\section{Arus kas dari aktivitas operasi}

laba (rugi) bersih

penyusutan aktiva tetap $\&$ amortisasi

$(8.399 .632 .285)$

6.798 .438 .993

laba (rugi) bersih operasi sebelum perubahan operasi kerja

$(1.601 .193 .292)$

perubahan modal kerja :

- piutang usaha

$(11.006 .853 .768)$

-penyisihan piutang usaha

8.806.223.384

-piutang lain-lain

-piutang ke PDAM

$-$

-persediaan

-biaya dibayar dimuka

-hutang jangka pendek

2.109.328.555

-hutang jangka panjang

4.138 .132 .767

1.964 .556 .084

Arus Kas Bersih yang Dihasilkan (digunakan) untuk aktivitas (I)

Aktivitas Investasi:

-Aktiva Tetap

$(1.562 .555 .250)$

-investasi

-aktiva lain-lain

Arus Kas Bersih yang Dihasilkan (digunakan) untuk aktivitas (II)

ARUS KAS DARI AKTIVITAS PENDANAAN

Aktivitas Pendanaan :

-Modal Tambahan

-laba (rugi) ditahan

308.290 .905

Arus Kas Bersih yang Dihasilkan (Digunakan) Untuk Aktivitas Pendanaan

308.290 .905

Kenaikan bersih kas dan setara kas (I+II+III)

(308.290.905)

Kas dan Setara Kas Pada Awal Periode

205.487.243

Kas dan Setara Kas Pada Akhir Periode

299.197 .173 
ARUS KAS DARI AKTIVITAS OPERASI

Laba (Rugi) Bersih penyesuaian untuk

Laporan Arus Kas 2016

Penyusutan aktiva Tetap \& Amortisasi

$(17.669 .266 .692)$

6.572 .014 .222

Laba (Rugi) Bersih Operasi Sebelum Perubahan Modal Kerja

(11.097.252.470)

Perubahan Modal Kerja

- Piutang Usaha

$(4.868 .454 .073)$

- Penyisihan Piutang Usaha

3.018 .766 .283

- Piutang Lain-Lain

$(15.342 .000)$

-Piutang ke PDAM

$(95.412 .632)$

- Persediaan

130.742 .292

-Biaya dibayar dimuka

-Hutang jangka Pendek

2.723.347856

-Hutang Jangka Panjang

10.378.274.213

Arus Kas Besih yang Dihasilkan (Digunakan) Untuk Aktivitaas Operasi (I)

174.669 .505

ARUS KAS DARI AKTIVITAS INVESTASI

Aktivitas Investasi

- Aktiva Tetap

$(203.392 .899)$

- Aset dalam Penyelesaian

(485.700.000)

- Investasi

- Aktiva Lain-Lain

Arus Kas Bersih yang Dihasilkan (Digunakan) Untuk Aktivitas Investasi

ARUS KAS DARI AKTIVITAS PENDANAAN

Aktivitas Pendanaan

-ModallTambahan

-Laba (Rugi) Ditahan

Arus Kas Bersih yang Dihasilkan (Digunakan) Untuk Aktivitas Pendanaan

Kenaikan bersih kas dan setara kas (I+II+III)

Kas dan Setara Kas Pada Awal Periode

$(689.092 .899)$

Kas dan Setara Kas Pada Akhir Periode

\subsection{Pembahasan}

SAK ETAP. Entitas tanpa akuntabilitas ialah entitas yang tidak memiliki akuntabilitas public signifikan dan menerbitkan laporan keuangan untuk tujuan umum (general purpose financial statement) bagi pengguna eksternal. Entitas yang memiliki akuntabilitas public signifikan dapat menggunakan SAK ETAP jika otoritas berwenang membuat regulasi mengizinkan penggunaan SAK ETAP. Pada perusahaan yang di ambil yakni PT. Air Manado dalam laporan keuangannya yakni laporan arus kas diterbitkan masih ada beberapa elemen laporan yang tidak ada dalam laporan arus kas pad tiga tahun terakhir di perusahaan PT.Air Manado. Pada laporan arus kas yang diterbitkan dalam tiga tahun terakhir perusahaan dalam bidang jasa tersebut meskipun belum secara utuh menerapkan semua menurut SAK ETAP tapi secara keseluruhannya elemen-elemen yang menurut SAK ETAP ada dalam laporan arus kas perusahaan PT. Air Mnado. PT. Air Manado juga membuat laporan keuangannya menurut SAK ETAP yakni Neraca, Laporan Laba Rugi, Laporan Arus Kas, Catatan Atas Laporan Keuangan, dan Laporan Perubahan Ekuitas. Penelitian ini juga di dukung dengan adanya penelitian terdahulu yang dilakukan oleh Pratiwi (2014) judul Analisis Penerapan SAK ETAP pada penyajian Laporan Keuangan PT. NICHINDO SUSAN MANADO menyatakan Neraca dan Laporan Laba Rugi tahun 2011 dan 2012, membuktikan bahwa perusahaan belum menyajikan laporan perubahaan ekuitas, laporan arus kas, dan catatan atas laporan keuangan (CALK) serta menjadi inkonsistensi dalam penyajian beberapa pos pada Neraca yang tidak diungkapkan dalam CALK. Adapun Penelitian terdahulu juga yang mendukung hasil penelitian tersebut. Wehantouw (2015) judul Analisis Laporan Arus Kas Operasi, Investasi dan Pendanaan Pada PT. Gudang Garam Tbk yang hasil penelitian menyatakan Menunjukan PT. Gudang 
Garam, pada umumnya memiliki laporan arus kas yang baik dapat dilihat dari setiap rata-rata perbandingan arus kas yang ada.

Penyajian Laporan Arus Kas. Terdapat 2 bentuk penyajian dalam membuat laporan arus kas, yang pertama metode direct (langsung) dan metode indirect (tidak langsung), perbedaan antara kedua metode terletak pada penyajian arus kas berasal dari kegiatan operasi. Dalam metode ini laba atau rugi neto disesuaikan dengan mengoreksi dampak dari transaksi non kas, penangguhan atau akrual dari penerimaan atau pembayaran kas untuk operasi di masa lalu dan masa depan, dan unsur penghasilan atau beban yang berkaitan dengan arus kas investasi atau pendanaan.

\section{KESIMPULAN DAN SARAN}

\subsection{Kesimpulan}

Hasil penelitian dan pembahasan yang ada, kesimpulan pada penelitian ini adalah sebagai berikut:

1. Pada PT. Air Manado, laporan arus kas tahun 2014 yang diterbitkan masih belum sepenuhnya seperti laporan arus kas menurut SAK ETAP karena ada tiga elemen atau pos yang tidak ada di dalam laporan arus kas PT. Air Manado yakni selisih kurs valuta asing, pembelian/penjualan aset tidak berwujud,dan penerimaan/pembayaran modal pinjaman.

2. Pada PT. Air Manado, laporan arus kas yang diterbitkan masih belum sepenuhnya seperti laporan arus kas menurut SAK ETAP karena ada tiga elemen atau pos yang tidak ada di dalam laporan arus kas PT. Air Manado yakni selisih kurs valuta asing, pembelian/penjualan aset tidak berwujud,dan penerimaan/pembayaran modal pinjaman.

3. Pada PT. Air Manado, laporan arus kas yang diterbitkan masih belum sepenuhnya seperti laporan arus kas menurut SAK ETAP karena ada tiga elemen atau pos yang tidak ada di dalam laporan arus kas PT. Air Manado yakni selisih kurs valuta asing, pembelian/penjualan aset tidak berwujud, dan pembayaran deviden.

4. Penerapan laporan arus kas berdasarkan SAK ETAP pada perusahaan PT. Air Manado pada umumnya sudah menyusun laporan arus kas sesuai dengan SAK ETAP,laporan arus kas membagikan manfaat bersifat informasi penerimaan dan pengeluaran kas dari aktivitasi operasi dan investasi pada PT.Air Manado.

\subsection{Saran}

Berdasarkan hasil penelitian dan pembahasan yang telah dilakukan :

1. Bagi PT. Air Manado agar sebaiknya mengikuti atau menerapkan secara keseluruhan penyusunan laporan keuangan menurut Standar Akuntansi Keuangan Entitas Tanpa Akuntabilitas Publik (SAK ETAP) tentang Laporan Arus Kas agar laporan keuangan yang dihasilkan sesuai dengan SAK ETAP dan menjadi lebih baik lagi.

2. Bagi peneliti selanjutnya diharapkan dapat meneliti dengan sampel penelitian yang lebih banyak, serta meneliti kelima laporan keuangan sesuai Standar Akuntansi Keuangan Entitas Tanpa Akuntabilitas Publik (SAK ETAP) secara keseluruhan agar mendapat hasil penelitian yang lebih baik.

\section{DAFTAR PUSTAKA}

Choi, Frederick. D.S. \& Meek, Gary K., 2010. Akuntansi Internasional Jilid 1. Edisi keenam. Jakarta. Salemba Empat.

Effendy, Rizal. 2014. Accounting Principle. Edisi Revisi. Rajagrafindo Persada.Jakarta. 
Hery. 2012. Cara Mudah Memahami Akuntansi (Inti Sari Konsep Dasar Akuntansi).Jakarta. Prenada Media Group.

Hillinger, Claude. 2010, The Crisis and Beyond: Thinking Outside the Box. Ejournal of Kiel Institute, 4(23), 1-63.

Ikatan Akuntansi Indonesia (AIA). 2009. Standar Akuntansi Keuangan Entitas Tanpa Akuntabilitas Publik. DSAK. Jakarta

Ikatan Akuntan Indonesia. 2014. Standar Akuntansi Keuangan Entitas Tanpa Akuntabilitas Publik (SAK ETAP). Jakarta: Ikatan Akuntan Indonesia

Meireny, Silvia. 2015. Analisis Penyusunan Laporan Keuangan

Berdasarkan SAK ETAP Pada Koperasi Pasar Gondanglegi. Skripsi. Universitas Islam Negeri Maulana Malik Ibrahim.Malang.

Pratiwi, Astalia, Ade. 2014. Analisis Penerapan SAK ETAP Pada Penyajian Laporan Keuangan PT. NICHINDO MANADO SUISAN. Skripsi. Universitas Sam Ratulangi. Manado.

Surya, 2012:6 Interpretasi Standar Akuntansi Keuangan (ISAK) Jilid 2. Edisi keenam. Salemba Empat. Jakarta.

Sunyoto, Danang. 2013. Teori, Kuesioner, dan Analisis Data Sumber Daya Manusia (Praktik Penelitian). Cetakan ke-2. CAPS. Yogyakarta.

Tukunang, Jeferson. 2014. Penerapan Laporan Arus Kas Berdasarkan Sak-Etap Pada UD. Berkat Anugerah Jurnal EMBA, 2(2), 828-839

Wehantouw, Andre. 2015. Analisis Laporan Arus Kas Operasi, Investasi dan Pendanaan Pada PT. Gudang Garam Tbk Jurnal EMBA, 3(1), 806-817 